Journal of Behavioral Decision Making

J. Behav. Dec. Making (2010)

Published online in Wiley InterScience

(www.interscience.wiley.com) DOI: 10.1002/bdm.709

\title{
Feelings of Dread and Intertemporal Choice
}

\author{
CHRISTINE R. HARRIS* \\ Department of Psychology, University of California, San Diego, California, USA
}

\begin{abstract}
It frequently has been observed that people discount future rewards relative to present rewards. However, the literature on intertemporal choices involving emotional upsets and losses is fraught with inconsistencies, with some studies finding similar discounting of gains and losses, and others reporting that participants elect to undergo negative experiences sooner rather than later. To help resolve these contradictions, time preferences for different types of aversive experiences (social rejection, embarrassment, pain, monetary and property loss) were examined in five studies. Most participants preferred to postpone monetary and property losses, but intertemporal choices for other unpleasant experiences showed highly variable responses, with some participants deferring them as long as possible, and many electing to experience them immediately. Time preferences for these negative experiences were correlated, but were independent of time preference for rewards. It is argued (following Loewenstein, 1987) that anticipation of dread plays a key role in many people's choices about timing of aversive experiences. This interpretation was supported by choices about when to learn of a very unpleasant event whose timing was fixed (Study 3), and by a novel preference reversal (Study 4). Study 5 examined how actual and hypothetical experiences of dread unfolded over time; the results were consistent with a dread-based interpretation of choices in the preceding studies. Copyright (C) 2010 John Wiley \& Sons, Ltd.
\end{abstract}

KEY WORDS dread; affect; intertemporal choice; time discounting; fear

\section{INTRODUCTION}

The term temporal discounting refers to weighing potential gains and losses less heavily when these events lie in one's future, rather than one's present. This tendency is thought to shed light on many problematic aspects of human behavior (Ainslie, 1992; Critchfield \& Kollins, 2001; Elster, 1999; Rachlin, 2000), illuminating issues of self-control in both people and animals (Navarick \& Fantino, 1976; Rachlin, 2000). There is a large and generally consistent set of findings on temporal discounting of rewards (for reviews, see Chapman, 1998; Frederick, Loewenstein, \& O'Donoghue, 2003). However, intertemporal choices involving negative events, such as monetary losses, pain, unpleasant emotions, and the like, have been explored much less. Moreover, the literature on this topic contains puzzles and apparent contradictions. The present paper attempts to shed

\footnotetext{
* Correspondence to: Christine R. Harris, Department of Psychology - 0109, University of California, San Diego, 9500 Gilman Drive, La Jolla, CA 92093-0109, USA. E-mail: charris@ucsd.edu
} 
new light on intertemporal choices involving negative events by exploring people's reactions to choices that involve a variety of unpleasant emotional experiences as well as monetary and other tangible losses.

While the vast majority of studies of intertemporal choices have asked about preferences for the timing of positive experiences or monetary gains, choices regarding negative events seem at least equally important. Indeed, many of the most-discussed real-world phenomena relating to intertemporal choice involve aversive outcomes (negative health effects, hangovers, financial ruin) as well as positive ones. Thus, a better characterization of intertemporal choices for negative events should help in using intertemporal choice research to illuminate important behaviors and cognitions.

\section{Studies of intertemporal choices for aversive experiences}

I begin by reviewing the relatively modest set of studies that have examined intertemporal choices for specific negative experiences using substantial temporal intervals. In a frequently cited study, Mischel, Grusec, and Masters (1969) asked both children and adults to make choices about the timing of a number of different "one-shot" aversive experiences. For adult participants, these "punishments" were eating a can of badtasting food, drinking a bitter liquid, and experiencing a painful "cold pressor" task. The average responses suggested that a large majority of participants would prefer to undergo these unpleasant experiences immediately. In another study, most adults, who were offered the choice of experiencing electric shocks immediately or delayed by several weeks, chose the immediate shocks. Mischel et al. (1969) interpreted these findings as reflecting an effort to minimize dread ("waiting for an aversive outcome is itself aversive," p. 372).

Yates and Watts (1975) noted the apparent contrast between the tendency of the participants to choose to have negative events occur immediately in Mischel et al. (1969), and the common finding that people tend to discount future rewards. They pointed out that the adult participants in the Mischel et al. study knew they would ultimately receive compensation (credit toward a requirement for experiment participation) in return for letting themselves be subjected to the aversive experiences. Thus, they suggest, the participants might have seen the aversive experience and the compensation as bundled together in a single package with a net positive utility (otherwise, Yates and Watts asked, why did participants not "resign" from the experiment? (p. 297)). To determine whether people discount unambiguously negative experiences that are not bundled with anything positive, Yates and Watts carried out a study that began by giving participants a sum of money "up front." Participants then chose between immediate surrender of a specified portion of their winnings, or a deferred surrender of a different amount of money. Participants exhibited a standard temporal discounting effect, i.e., they chose to accept a larger loss when the loss was scheduled to occur later in time.

Very similar results have been reported in two other studies that used hypothetical monetary rewards and appear free of the bundling problem noted by Yates and Watts (Ostaszewski \& Karzel, 2002; Thaler, 1981). Ostaszewski and Karzel (2002) examined both temporal and probabilistic discounting of large hypothetical losses (ranging from $\$ 200$ to $\$ 30000$, occurring with probabilities ranging from 5 to $95 \%$ ). Participants made two-alternative choices between various risk/loss combinations, stipulated to occur either immediately or at delays ranging from 1 month to 10 years. Delayed losses were substantially discounted, and the hyperbolic discounting model commonly used to fit discounting of rewards (Myerson \& Green, 1995; Rachlin, Rainieri, $\&$ Cross, 1991) fit the data well. The rate of discounting for smaller losses was steeper than for larger losses, mirroring the effects of reward size on discounting rate (Chapman \& Winquist, 1998; Green, Myerson, \& McFadden, 1997; Kirby \& Marakovic, 1996).

\section{Possible interpretations}

One reasonably parsimonious interpretation of the three results described above would be that aversive events in the future are discounted in just the same way as future rewards, and studies suggesting otherwise have 
been misleading due to various complexities in the studies. However, other hypotheses deserve consideration as well. Monetary losses (the kind examined by Ostaszewski \& Karzel, 2002; Yates \& Watts, 1975, and others) may differ from the non-monetary harms that Mischel et al. studied in several ways that might be relevant to intertemporal choices.

First, the prospect of a monetary loss may not elicit dread or fear to the same degree as other kinds of aversive experiences. Thus, if people choose to undergo aversive experiences sooner rather than later in order to reduce the experience of dread, this might not enter into their choices for monetary losses. One reason why threat of monetary loss might not invoke dread is that people may anticipate (correctly or incorrectly) that the effects of even a large monetary loss would actually be spread over a very long period of time and thus diluted in their impact. For example, the result of a catastrophic loss might be aversive and very long lasting, but may not be acutely painful at any time.

A second, closely related possibility is that people may (quite rationally, it might be argued) view the effects of losing money (or perhaps other tangible assets) as something that would cause a small but essentially permanent reduction in utility or pleasure. Such a reduction would commence when the loss occurred and continue indefinitely (in economic terms, the loss of a durable good). If so, the best way to maximize average (even if undiscounted) future happiness is simply to postpone such a loss for as long as possible. By contrast, brief and time-limited aversive experiences, such as eating dog food or experiencing an electric shock, do not have this feature.

A third possibility relates to the economic concept of the time value of money. Participants with some exposure to economic theory, or even just some experience with household finances, may reason that because money can potentially earn interest, all else being equal it would be irrational to forego the opportunity to receive money as soon as possible, and discharge debts as late as possible. ${ }^{1}$

These accounts are not mutually exclusive, of course. For example, it could be that people prefer to take non-monetary punishments immediately, in order to minimize dread, and prefer to postpone monetary losses as a way to maximize average future utility and retain the time value of the money.

One study (Loewenstein, 1987) offers encouragement for the first hypothesis mentioned above, and partly inspired the present investigation. Loewenstein asked 30 participants how much money they would pay now to prevent ever experiencing each of three undesirable future outcomes ( $\$ 4$ loss, $\$ 1000$ loss, or electric shock), or to obtain each of two desirable future outcomes ( $\$ 4$ gain or kiss from favorite movie star). Each outcome was stipulated to be scheduled for some particular delay ranging from none to 10 years. The mean price participants were willing to pay to avoid the shock was approximately constant for delays of up to 3 days, but then increased significantly for a 1 year delay, and increased further at 10 years. By contrast, to avoid monetary losses, participants showed only conventional temporal discounting (paying less, the greater the delay of the loss). As Loewenstein pointed out, one interpretation is that participants factored in dread (or "anticipal pain," a term coined by Jevons, 1905), which made the delayed shock more aversive in its total impact than the immediate shock. He also made several intriguing theoretical observations about what happens when a decision maker seeks to optimize the utility of a future experience, which is not only subject to temporal discounting but also supplemented by a positive or negative anticipatory utility.

The possible contrast between monetary and non-monetary costs also bears on suggestions of Metcalfe and Mischel (1999), who distinguish affectively charged "hot values" and cognition-based "cool values." According to these authors, temporal discounting is typically steeper for hot-valued as against cool-valued outcomes. From this perspective, which was developed mostly in the context of analyzing rewards rather than losses, one might expect temporal discounting to be shallower for monetary losses than for more affectively charged negative events, rather than the reverse. Closely related to this hot/cool distinction is the idea of

\footnotetext{
${ }^{1}$ Temporal discounting for monetary gains is normally far steeper than the interest rate for money, and it is also non-exponential in character, suggesting that interest considerations alone cannot account for intertemporal choices; nonetheless they may contribute, affecting monetary and non-monetary choices differently.
} 
"visceral factors" in behavior choice emphasized by Loewenstein (1996) and the distinction between affectrich and affect-poor choices (Rottenstreich \& Hsee, 2001). These connections will be discussed further in the General Discussion below.

The present paper reports five studies examining intertemporal choices, focusing on losses and negative experiences as well as positive rewards. The goal was to shed light on some of the apparently discrepant findings in the literature, by contrasting intertemporal preferences for monetary versus non-monetary outcomes, and to test the idea that dread-minimization plays a role in certain intertemporal choices.

\section{STUDY 1: BINARY TEMPORAL CHOICES}

Study 1 examined intertemporal choices for monetary gains, monetary losses, and several different unpleasant non-monetary experiences (physical pain, interpersonal rejection, and embarrassment). Participants chose between different pairs of alternative temporal placements of each type of experience.

\section{Method}

Participants

Participants were recruited from the StudyResponse.com Internet research panel (Stanton \& Weiss, 2002). ${ }^{2}$ This is a demographically diverse research panel composed of adults of all ages, residing primarily in the US (in our sample $85 \%$ of respondents were from the US and 9\% from Canada). One hundred eighty-four participants completed a Web-based questionnaire in return for enrollment in a lottery with a $\$ 100$ first-place cash prize and a $\$ 50$ second-place prize.

\section{Procedure}

Participants completed a series of demographic questions and were then asked about five hypothetical events, one positive and four negative. The goal was to sample fairly broadly from the range of aversive experiences. The topics chosen were: pain (Experience painful bee sting); monetary gain (Win \$100 door prize tonight); monetary loss (Lose \$100 from your wallet); embarrassment (Have something very embarrassing happen to you); and interpersonal rejection (Your closest friend tells you they want nothing more to do with you). For each of these five items, participants were asked three questions: Would they prefer the event to take place (1) tonight or in 1 week?; (2) in 1 week or in 1 year?; and (3) tonight or in 1 year? These 15 questions were posed to participants in a random order. Participants responded using a 7-point scale, where 1 meant "definitely prefer" the earlier option, 4 meant "indifferent," and 7 meant "definitely prefer" the later option.

\section{Results and discussion}

Figure 1 shows the proportion of participants choosing each of the alternatives for each choice. Participants who preferred a delay for any particular temporal option also tended to prefer a delay for the other options relating to that same experience. (Spearman correlations across participants between responses to questions about the same experience ranged between .50 and .80.) Several of the hypotheses discussed in the

\footnotetext{
${ }^{2}$ Internet sampling methodology is increasingly common in all areas of psychology and numerous parallel lab/web replications have been reported (Krantz \& Dalal, 2000). However, since the method has not been heavily used in the study of temporal discounting, it seemed prudent to replicate a well-established finding before examining novel questions. Using the general methods described below, and approximately 900 participants from the same participant pool, in a preliminary study not reported here, I examined the effect of reward size on temporal discounting for hypothetical monetary rewards, following Kirby and Marakovic (1996). The results closely paralleled the findings of Kirby and Marakovic.
} 

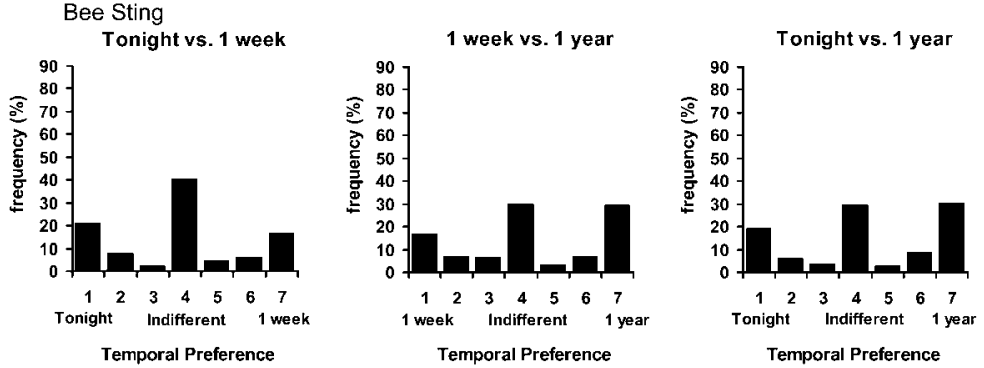

Embarrassment
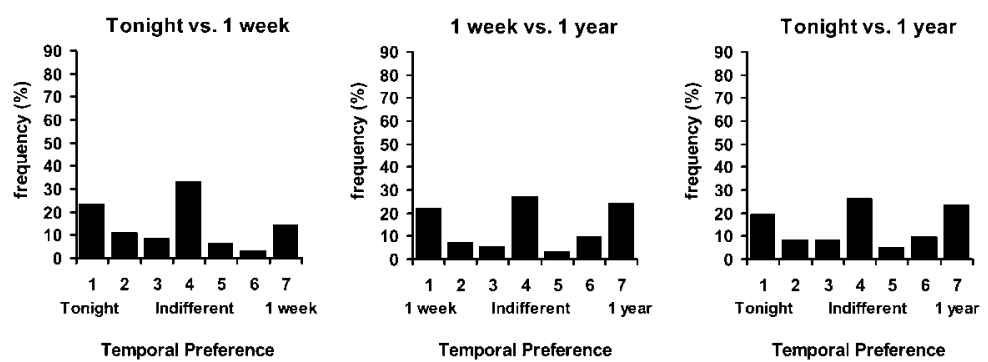

\section{Friend}
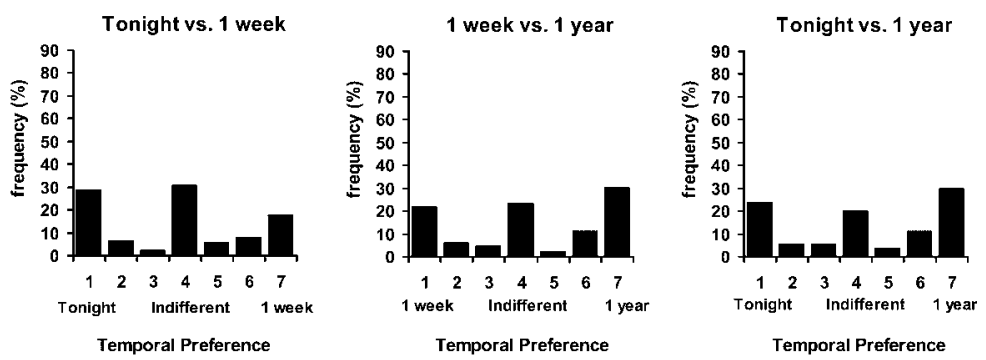

Lose $\$$
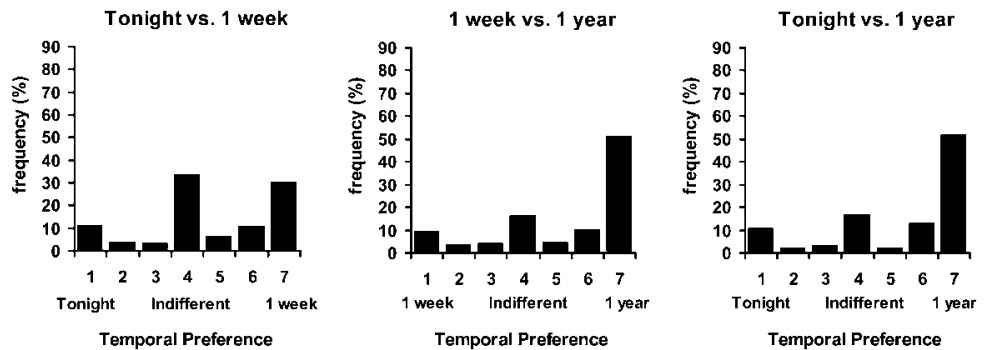

$$
\text { Win } \$
$$
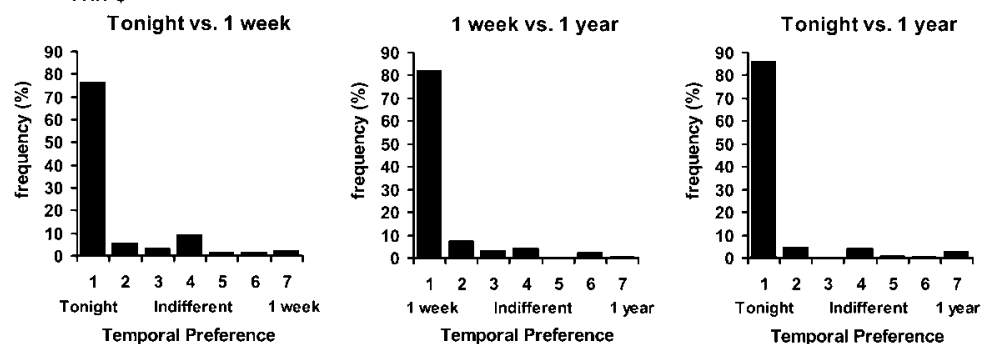

Figure 1. Proportion of participants choosing each of the available options for the 15 options presented in Study 1 
Journal of Behavioral Decision Making

Table 1. Spearman correlations of responses to the immediate vs. 1 week choices for the five categories of experience in Study 1

\begin{tabular}{rccccc}
\hline & Sting & Win $\$ 100$ & Lose $\$ 100$ & Embarrass & Reject \\
\hline Sting & 1 & -.04 & $.38^{* *}$ & $.34^{* *}$ & $.32^{* *}$ \\
Win \$100 & & 1 & -.14 & $.28^{* *}$ & .04 \\
Lose \$100 & & 1 & 1 & $.23^{* *}$ \\
Embarrassment & & & $.32^{* *}$ \\
Reject & & & & 1 \\
\hline
\end{tabular}

${ }^{* *} p<.01$

Introduction predict that there should be a greater tendency to postpone monetary losses as compared to physical pain, embarrassment, and social rejection. The data supported this prediction. For each of the three temporal options, participants showed a significantly stronger tendency to postpone the monetary loss than each of the other three types of losses (all comparisons were significant by Wilcoxon signed ranks test at $p<.001)$.

As Figure 1 discloses, aggregate responses to all of the non-monetary questions showed distinctive Wshaped distributions, with the most commonly selected responses being 1 (definitely prefer sooner), 4 (indifferent), and 7 (definitely prefer later), and relatively few participants picking the other four responses ( 2 , 3,5 , and 6). The consistency of responses to the three different temporal interval choices was also examined. For each type of gain or loss, there were three questions, permitting six different possible answers. Of these six, two represent violations of transitivity (e.g., preferring 1 week to now, preferring 1 year to 1 week, but preferring now to 1 year.) These two "irrational" patterns of responses were chosen with a reassuringly low frequency (.5-3.3\%, across scenarios).

The correlations between tendencies to postpone different experiences are presented in Table 1, which shows the data only for the immediate vs. 1 week choice (very similar patterns of correlations were found for each of the other two delay-pair options). There was no significant correlation between temporal choices for monetary gains and the other choices, but this may simply reflect the lack of variability in responses to the monetary gain questions. However, as seen in the table, there were modest but significant correlations between the tendency to postpone any one harm or loss and the tendency to postpone any other (monetary losses included). These results are reminiscent of the correlations observed by Chapman and colleagues (Chapman, 1996; Chapman \& Elstein, 1995), which will be described in the General Discussion below. They clearly are consistent with the view expressed by Frederick et al. (2003) that an assessment of preferences that relies exclusively on preferences for cash rewards may leave out important individual differences.

There was a reliable correlation between participants' income and their choices relating to monetary loss: higher income was associated with choosing to postpone the $\$ 100$ loss (Spearman's correlation was significant at $p<.05$ for both choices involving 1 year). This result is superficially puzzling: if one has more money, the $\$ 100$ loss presumably should matter less. However, temporal discounting often has been found to be steeper for smaller sums (e.g., Chapman \& Winquist, 1998; Kirby \& Marakovic, 1996) and for participants with higher income, the perceived magnitude of $\$ 100$ is presumably smaller. An anonymous reviewer pointed out another possible causal pathway: the greater financial sophistication indexed by choosing to postpone monetary losses may predispose people to earn more money.

\section{Summary}

The median participant reported indifference as to whether non-monetary aversive experiences would take place immediately or at a delay (1 week or 1 year). However, a substantial proportion of participants strongly preferred to have these experiences immediately, while another substantial group preferred to delay them. 
Comparing the results to those of Mischel et al. (1969), it appears that more participants in the present study sought to postpone aversive experiences. However, the summary data reported by Mischel et al. do not allow one to compare the distributions in the two studies in any detail. Loewenstein (1987) found that the average payment his participants would offer to avoid an unpleasant experience was greater when the experience was delayed by 1 or 10 years. The present results confirm that a preference for postponement does indeed characterize a large number of people, while at the same time indicating that this preference is far from universal.

For a monetary loss, on the other hand, postponement was the overwhelmingly preferred option, with the median participant indicating a strong preference for a 1-year postponement over either immediate or 1-week delay. Thus, the present data are in good qualitative agreement with the findings of Thaler (1981), Yates and Watts (1975), and Ostaszewski and Karzel (2002) for monetary losses.

\section{Implications for ideas in the temporal discounting literature}

Together, the findings of this study shed considerable light on the conflicting claims noted in the literature review above. The present data suggest that whether people choose to postpone aversive events or to undergo them immediately does not hinge on having the negative event bundled together with a positive inducement (as Yates \& Watts, 1975 had suggested in reference to the study by Mischel et al., 1969). Neither does it seem to matter whether the participant views the choice as hypothetical (as in the present studies, as well as those of Thaler, 1981, and Ostaszewski \& Karzel, 2002) or real (as in the studies of Yates \& Watts, 1975, and, it appears, Mischel et al., 1969). Rather, the critical factor seems to be whether the harm involves a loss of money (in which case the most common preference is to postpone as long as possible) versus some other kind of unpleasant experience (in which case substantial proportions of people choose to undergo the experience immediately).

\section{STUDY 2: SIX-ALTERNATIVE TEMPORAL CHOICES}

To provide further evidence on the apparent contrast between non-monetary and monetary losses, as revealed in Study 1, the second study used a somewhat different method of assessing intertemporal choice. Rather than having participants choose between a two-alternative forced choice for when a harm would occur, participants were asked to pick one of six possible temporal placements: right now, tomorrow, 1 week from now, 1 month from now, 1 year from now, or 5 years from now. Seven different scenarios were presented. In addition to monetary losses and monetary gains, physical pain, embarrassment, and interpersonal rejection, ${ }^{3}$ two additional scenarios were introduced. One consisted of the loss of a highly valued personal property (personal photos). This would be expected to represent an emotionally "hot-valued" loss, but one whose consequences would most naturally be viewed as a long-lasting decline in consumption (loss of a durable good). The second consisted in a non-monetary positive experience: receipt of praise. Participants also were asked a number of questions relevant to self-control in their daily lives, to explore the relationship of selfcontrol to individual differences in intertemporal choices.

\section{Method}

\section{Participants}

One hundred sixty-four participants from the same participant pool, but who had not been included in Study 1 , participated in this study.

\footnotetext{
${ }^{3}$ The interpersonal rejection scenario was slightly modified from the previous study. Rather than asking about rejection by the participant's closest friend, participants were asked about rejection by a "fairly close friend;" data from another parallel study not reported here suggested that the former scenario was viewed as so extreme by some respondents that they found the question difficult to respond to.
} 
Table 2. Scenarios and median preferences in Study 2

Receive a very painful bee sting, causing no lasting injury

Lose an irreplaceable personal photograph that you particularly like

Tomorrow

5 years

Accidentally spill a glass of water on yourself in a restaurant

A fairly close friend tells you they want nothing more to do with you

Tomorrow

Realize you just lost $\$ 100$ from your wallet

Win $\$ 500$ drawing at a store

Receive sincere praise from someone whose opinion means a great deal to you

Now

\section{Procedures}

Participants were asked about the seven scenarios listed in Table 2. In addition to demographic questions, participants also were asked questions relevant to impulsivity and self-control, including whether they smoked cigarettes (currently or in the past); whether they had ever put off needed dental work merely because they did not feel like having it done soon; whether they voted regularly; and whether the participant considered himself or herself to be a procrastinator. They were also asked about exposure to economics and psychology.

\section{Results}

Table 2 shows median temporal preferences for the seven scenarios. For monetary gains and losses, the median participant's choices were generally in line with conventional temporal discounting: The median participant chose to put off losses as long as possible, and sought to experience gains without any delay.

For one-shot aversive experiences (embarrassment and bee sting), on the other hand, the median participant elected to undergo the experience tomorrow. The median was not fully representative of the entire distribution, however. Figure 2 shows the distribution of temporal preference responses for all six scenarios. As suggested by the medians, choices for monetary gain showed an overwhelming choice of immediate, and the results for praise look much the same. For a $\$ 100$ loss, the great majority sought to postpone. By contrast, bimodality is apparent in the responses to the bee sting scenario and the spill water scenario, and to a smaller degree, the loss of photograph and loss of friend scenarios. Thus, for some non-monetary harms the median response (tomorrow) conceals considerable variability among subjects.

\section{Individual differences}

To explore individual differences, Spearman correlations between the choices were computed (Table 3). The results revealed a significant correlation between choices relating to positive experiences. Responses pertaining to temporally discrete harms and losses also were generally correlated with each other.

One might suppose that exposure to economics (implying some understanding of the concept of the time value of money) would help predict responses to the questions involving money. Only six participants indicated they had majored in economics in college, but $22 \%$ reported "some coursework." This training had no detectable effect. Indeed, those who reported economics coursework were slightly (but non-significantly) less likely to choose the economically rational option of postponing a $\$ 100$ loss as long as possible.

Responses to self-control related questions showed a few positive relationships to intertemporal nonmonetary choice questions (but no relationship to intertemporal choices relating to monetary rewards).

\section{Discussion}

In most respects, the main results of Study 2 are in broad agreement with those of Study 1, and support the conclusions based on that study regarding ideas in the prior literature that were suggested above. First, 


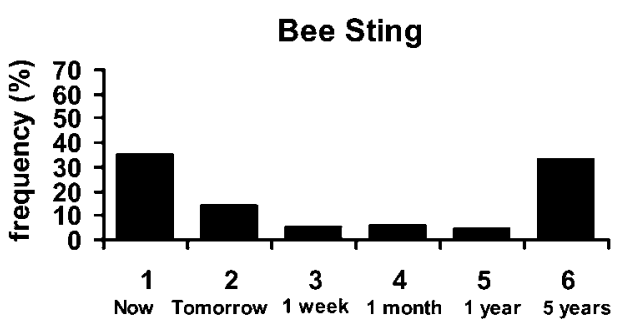

Temporal Preference

Water

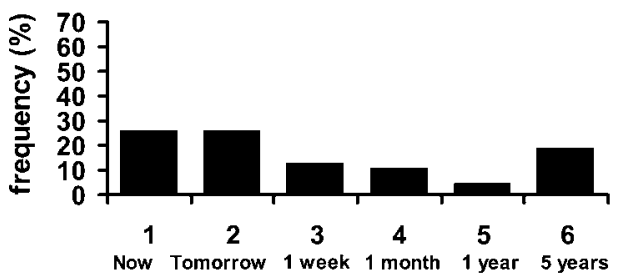

Temporal Preference

Lose \$

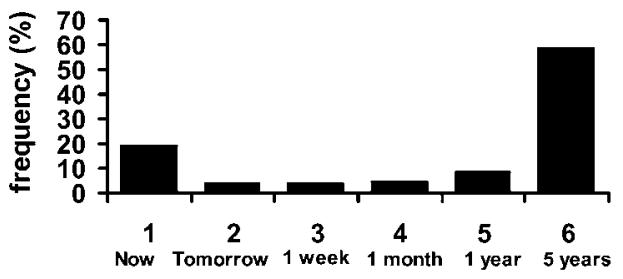

Temporal Preference

Praise

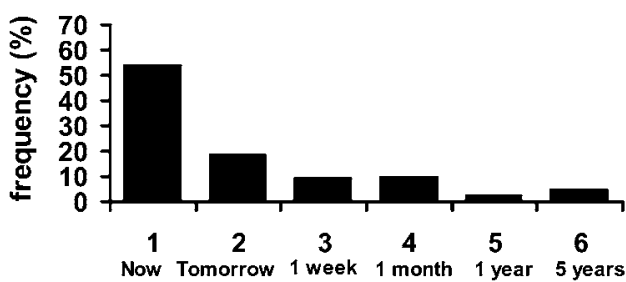

Temporal Preference

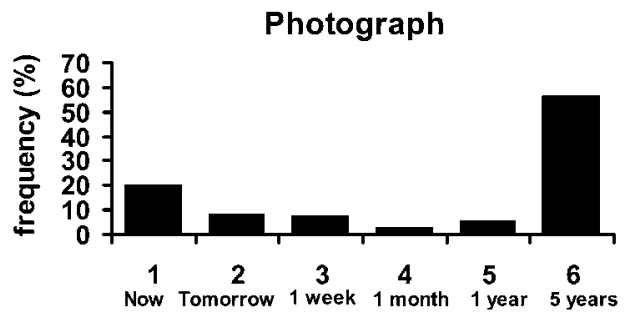

Temporal Preference

Friend

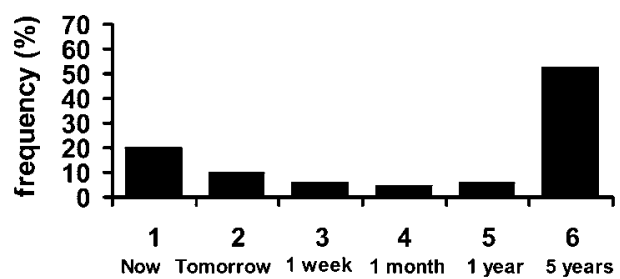

Temporal Preference

Win \$

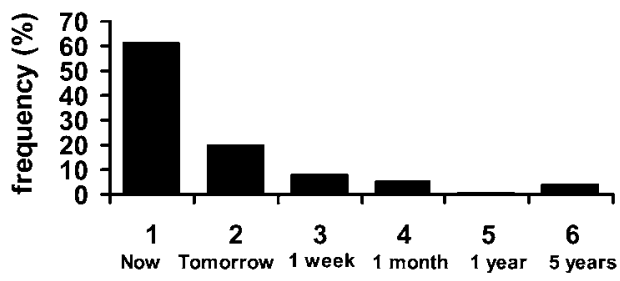

Temporal Preference

Figure 2. Proportion of participants choosing each of the available options for the seven choices presented in Study 2

intertemporal choices for monetary gains or losses conform well to the standard expectations from temporal discounting alone. Second, for unpleasant but non-monetary experiences, a substantial proportion of people elect to undergo these experiences sooner rather than later, while a sizable number of people elect to postpone them.

Examined in finer detail, however, there are a few puzzling differences. In Study 2, where participants were forced to pick a preferred time for an aversive event, but did not indicate the strength of their preference, response distributions were clearly bimodal. In Study 1, on the other hand, responses (on a bipolar scale 
Journal of Behavioral Decision Making

Table 3. Spearman correlations between preferred temporal placement of the seven scenarios in Study 2

\begin{tabular}{lccccccc}
\hline & Bee sting & Lose photo & Spill water & Friend rejects & Lose \$100 & Win \$500 & Receive praise \\
\hline Bee sting & 1 & .06 & $.38^{* *}$ & $.25^{* *}$ & .15 & .05 & -.09 \\
Lose photograph & & 1 & .04 & .15 & $.43^{* *}$ & -.07 & -.04 \\
Spill water & & & 1 & $.20^{* *}$ & $.20^{*}$ & .11 & -.07 \\
Friend rejects & & & & 1 & $.25^{* *}$ & -.11 & $-.26^{* *}$ \\
Lose \$100 & & & & & 1 & .01 & -.15 \\
Win \$500 & & & & & & & $.28^{* *}$ \\
Receive praise & & & & & & & 1 \\
\hline
\end{tabular}

${ }^{* *} p<.01$.

ranging from strongly prefer to undergo the experience immediately through indifference through strongly prefer to postpone) actually appeared trimodal (peaks at both ends and at indifference). This issue will be discussed further in the General Discussion.

A non-monetary gain (praise) elicited choices much like a monetary gain, with strong correlations between responses to the two scenarios. Most participants elected to postpone loss of an emotionally charged piece of tangible property (irreplaceable personal photo). An obvious "rational" explanation for such a preference would be the preference for postponing loss of a durable good in order to minimize the reduction in the overall utility it delivers over time. The same interpretation may well account for the common (and correlated) preference for postponing the interpersonal rejection (which could be viewed at least partially as a loss of a durable good, i.e., friendship). It is not entirely clear what accounts for participants' apparently greater tendency to postpone the loss of a friendship in the current study as compared to their choices in the somewhat similar scenario included in Study 1. It may be that the wording in Study 1 (closest friend) led participants to view the rejection as a (dreadable) painful experience to a greater extent than the wording in Study 2 (fairly close friend); of course, this is mere speculation.

\section{STUDY 3: CHOOSING WHEN TO FIND OUT}

The results of the first two studies show that for monetary losses, people almost universally seek to postpone the loss, whereas for non-monetary losses, and perhaps especially those involving emotional or physical pain or discomfort, a sizable fraction of people choose to undergo the experience earlier rather than later. One interpretation, advocated by Loewenstein (1987), is that when presented with a choice involving a delayed experience positive or negative, people assess the desirability of this choice by considering not only the experience itself (presumably discounted according to its delay) but also bundle in their predicted anticipatory experience. For negative experiences, and perhaps especially for those that have some strong "visceral" aspect (Loewenstein, 1996), this includes an element of dread or anxious anticipation. Thus, in the first two studies, the choice (by some) to undergo a negative experience immediately is accounted for by an effort to curtail the period over which dread is experienced.

However, two natural alternatives also deserve consideration. First, it would seem plausible that there is often considerable social pressure to avoid postponing unpleasant events (such choices being viewed as "weak" or "childish"). The choice to have an unpleasant event take place sooner rather than later may reflect conformity to this social pressure on the part of some participants. Second, each of the scenarios used in the preceding studies has complexities unique to the situation. For example (as an anonymous reviewer of an earlier version of this paper pointed out), if a friend is going to reject you at a later point in time, you might regard the person as no friend at all, and for that reason choose to have the friendship end sooner rather than later. For each scenario, there may well be some interpretation of this sort, which could explain a preference to get the experience over with without invoking dread and its minimization. To provide a converging test of 
the dread-minimization account, Study 3 took a different tack from the earlier studies. Participants did not choose when a negative experience would take place. Instead, the timing of the negative experience was a given (it would occur 30 days in the future), and participants were asked to choose when they wished to be informed of the negative event (ranging from now to 30 days in the future). As discussed below, a rationale was included in the scenario to make these choices at least somewhat plausible.

\section{Method}

Participants

Participants were 352 new individuals from an Internet sample.

\section{Design and procedure}

After answering demographic questions, participants were instructed as follows: Imagine the following scenario. Suppose you are walking down the street and you are bitten by a dog, whose teeth break your skin. You seek the care of your doctor. Your doctor decides that due to a viral infection which is spreading among dogs in your community, you will need to have a very painful series of shots. The shots are something like rabies shot, but they are for a different sort of virus - not rabies. Unlike rabies shots, these shots need to be administered over a 24-hour period, starting 30 days after the dog bite. This will mean that you will experience extremely intense pain in 30 days. However, the shots are effective, and now that they have been scheduled to happen in 30 days, there should be no problem in preventing any serious medical consequences for you. We would like you to reflect on, and answer, the following question: when would you like your doctor to decide to tell you that the shots will be very painful? Please assume that telling you about how painful they will be will not allow you to do anything to reduce their painfulness. The question is just: when would you want to be told that the experience is going to be extremely painful?

They were asked to choose between five options: (1) immediately before the shots are to be given (30 days from now); (2) the evening before the shots; (3) the previous morning before the shots; (4) 1 week before the shots are to be given; (5) right now (30 days before the shots are to be given).

Next, all participants who did not select "immediately before the shots are to be given" were asked to explain why they did not choose this option (typing their responses in text format). Then, all participants who did not select "right now (30 days before the shots are to be given)" were asked to explain why they did not choose this option (also text responses).

\section{Results and discussion}

Table 4 shows the proportion of participants choosing each of the five options. As seen in the table, almost half of the participants chose to delay being told about the painfulness of the shots.

The responses that participants provided for not wanting to be immediately informed were examined. Two research assistants, who were unfamiliar with the hypothesis of this work, independently coded responses for the occurrence of dread. This was defined for the coders with material drawn from dictionary definitions, "To fear greatly, To feel extreme reluctance to meet or face, To be apprehensive or fearful" (from the Webster's 9th New Collegiate Dictionary; Dread, 1990) and, "To be in terror of. To anticipate with alarm, distaste, or reluctance" (The Free Dictionary; Dread, 2009). Coders were instructed that if they were uncertain whether a response was dread, or if they could not tell, then they should not code it as dread. A point-biserial correlation revealed a high inter-rater reliability of $r(173)=.82$. According to both coders, $41 \%$ of participants explicitly described minimizing dread as a reason for not wanting to learn about the painfulness now. Here are some sample quotes that seem fairly representative of these: "would be worrying for 30 days," "That is too long of a time and I would probably think about it too much and freak out," "would have 30 days to dread the day and wishing it were already over," "because I do not want to put me in the tension for 1 month," "So I didn't have 


\section{Journal of Behavioral Decision Making}

Table 4. Percent of participants choosing each temporal option in Study 3

\begin{tabular}{lc}
\hline Temporal choice for learning about painfulness & Percent response $(n)$ \\
\hline 30 days in advance (now) & $50.6 \%(n=178)$ \\
Week before shots & $4.0 \%(n=14)$ \\
Evening before shots & $9.4 \%(n=33)$ \\
Morning before shots & $2.8 \%(n=10)$ \\
Right before shots & $33.2 \%(n=117)$ \\
\hline
\end{tabular}

time to stress about it," and "so that it would not be playing on my mined [sic]." Many of the explanations not coded as dread appeared to be mere restatements of the fact to be explained (e.g., "I prefer to make it immediately") or too cryptic to be classified (e.g., "immediate prevention" and "What would knowing right now accomplish?"), and no other major response categories besides dread could be discerned among the responses.

Participants who did not choose the last possible moment to be informed of the unpleasant event were asked to explain why they did not make that choice. Two blind coders then sorted these responses into categories. The number one reason stated for wanting to know sooner was to mentally prepare for the event (46.6\% based on Coder 1 and $50.4 \%$ based on Coder 2).

The results clearly support the idea that the goal of minimizing dread or "anticipal unpleasure" can play an important role in choice behavior. It is important to note that the results do not rule out the idea that the unpleasurable aspects of the experience itself are subject to temporal discounting. In the current study, such discounting would not have affected choices, because the time of the unpleasant event was fixed and not open to choice. The results also suggest that people often reject the idea of being informed immediately before the event because, even though this would minimize dread, it provides inadequate opportunities for mental preparation.

\section{STUDY 4: PREFERENCE REVERSALS}

Thus far, I have been arguing (in agreement with Loewenstein and Mischel, among others) that people often choose to undergo unpleasant experiences sooner rather than later for a hedonic reason: to minimize the experience of an additional negative cost—dread—over the period that the experience is being anticipated. To shed further light on this analysis, and to distinguish it from competing accounts (such as the idea that people choose the immediate option to conform to social pressures), the present study asked whether it might be possible to elicit a novel form of preference reversal. Figure 3 shows the situation in which a person chooses between two unpleasant alternatives, one scheduled to occur immediately, and another (slightly less aversive) experience scheduled to occur in 1 week. Following Loewenstein (1987), the figure represents anticipated dread as a psychic cost (a negative utility labeled D) that a person experiences during the time leading up to an anticipated aversive event (which carries its own negative utility, labeled E). Moreover, it will be assumed that dread occurs mostly in close proximity to the event (a point that will be directly examined in Study 5). ${ }^{4}$ When given the choice between experiencing the unpleasant event $(\mathrm{E}+)$ immediately and experiencing a slightly less unpleasant event (E), 1 week from now, a person should choose $\mathrm{E}+$. (This predicted choice is marked with an asterisk in the figure.) The reason is that when the anticipated unpleasantness of the dread is bundled with the unpleasantness of the event $\mathrm{E}$ itself (even after any possible

\footnotetext{
${ }^{4}$ This provides only a rough gloss on the precise assumptions under which the preference reversal would be expected; see Loewenstein (1987) for a discussion of possible utility functions that would incorporate both dread and temporal discounting.
} 

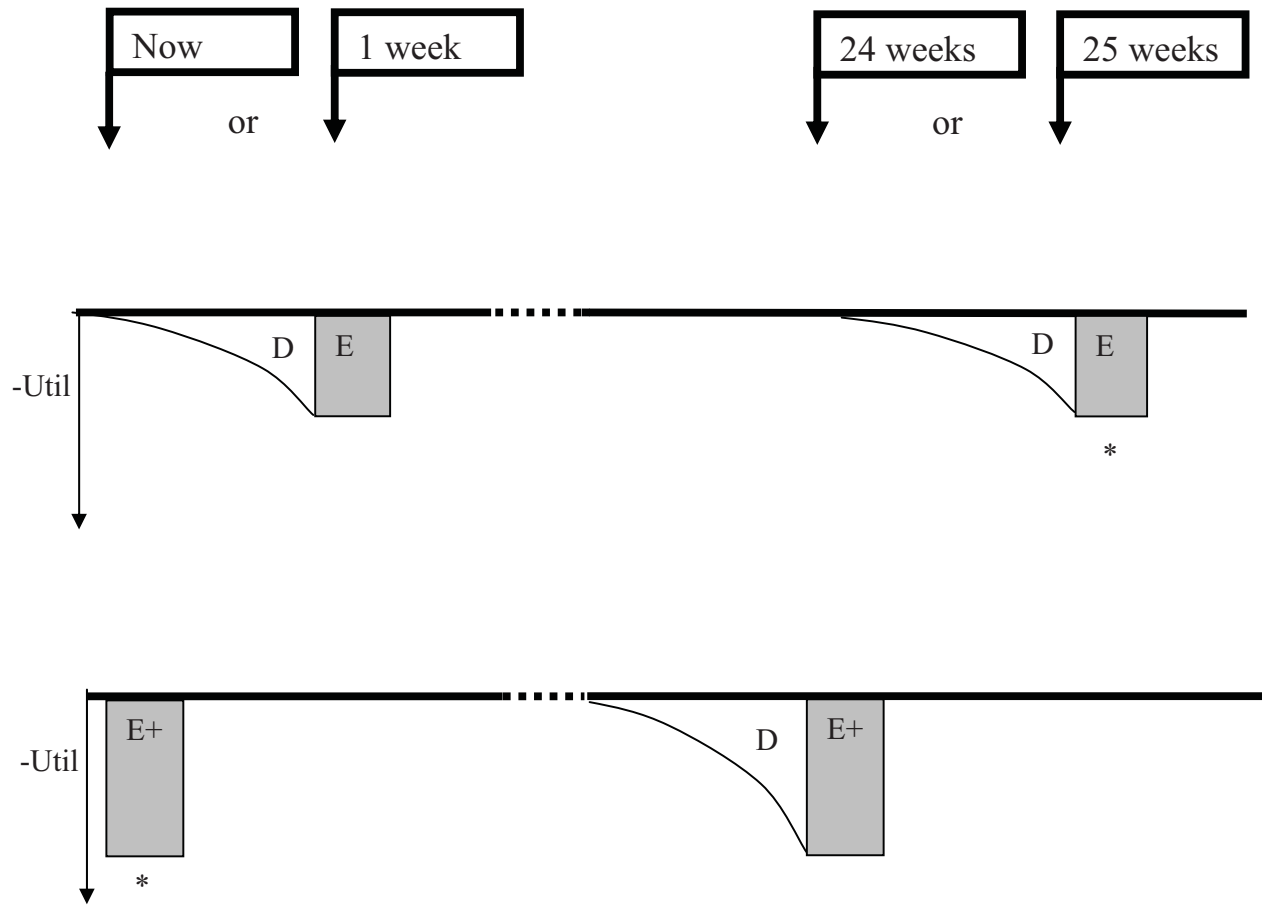

Figure 3. In Study 4, anticipated experience of dread (D) as an unpleasant event (E: shaded boxes on top row) or a more unpleasant event (E+: shaded boxes on bottom row) approaches. In Choice 1, participants choose between the top and bottom options presented on the left side of Figure 3. In Choice 2, participants chose between the top and bottom options presented on the right side of Figure 3. The choices are identical except for the delay added to choice 2. Following Loewenstein (1987), dread is assumed to grow sharply with temporal proximity, and the person chooses so as to minimize the total aversiveness associated with the experience and the dread (total area of bar and curve). This predicts that people should choose the larger immediate punishment in Choice 1, and the smaller delayed punishment in Choice 2 (predicted choices are marked with ${ }^{*}$ )

temporal discounting of these experiences), the summed unpleasantness exceeds the aversiveness of the immediate unpleasant experience $\mathrm{E}+$ (since it does not come bundled with any dread).

On the other hand, the situation is different when the same set of options is offered with a 24-week delay inserted before both events. Now the more unpleasant event $\mathrm{E}+$ is bundled with dread (and possibly even more dread than is $\mathrm{E}$, if the magnitude of the dread is scaled with the unpleasantness of the event, as depicted in the figure.) So now a person has every reason to prefer $\mathrm{E}$ over $\mathrm{E}+$.

Thus, a preference reversal is directly predicted by a hedonic (dread) interpretation. However, the reversal would not seem to be predicted by the idea that people believe that it is more socially desirable to choose to undergo negative events earlier rather than later. Study 4 asked whether this preference reversal occurs.

\section{Method}

\section{Participants}

Participants were 193 new individuals from the same population described in Study 1.

\section{Design}

Participants answered demographic questions, followed by a prescribed sequence of choices involving two hypothetical electric shocks (the sequence is shown in the directed graph in Figure 4). The first question, 
asked of all participants, was whether they would prefer to undergo a 40-V electric shock (described as very painful but causing no permanent injury) either right now or 1 week from now. Participants choosing "now" were asked whether they would still prefer the 40-V electric shock now if the alternative in 1 week were a smaller $(36 \mathrm{~V})$ shock. Those indicating that they would do so were offered the choice of $40 \mathrm{~V}$ now against a still smaller $(32 \mathrm{~V})$ shock delayed by 1 week. Next, all participants who chose "shock now" in response to the initial question were asked if they would prefer a $40-\mathrm{V}$ shock in 24 weeks or a 36-V shock in 25 weeks.

The participants who responded to the initial ( $40 \mathrm{~V}$ now vs. $40 \mathrm{~V}$ in 1 week) question by choosing " 1 week" were offered questions that symmetrically mirrored those offered to participants choosing immediate shock. That is, they were asked whether they would still choose to defer the shock if the immediate option were reduced by $4 \mathrm{~V}$, and if so, then by $8 \mathrm{~V}$, and then asked about their preference for $36 \mathrm{~V}$ in 24 weeks versus $40 \mathrm{~V}$ in 25 weeks.

Participants were told to assume that the reduced voltage shocks would be less painful "in proportion to the voltage" (while this instruction was premised on scientifically dubious assumptions, participants seemed to accept it on face value; cf. Ellermeier, Westphal, \& Heidenfelder, 1991.)

\section{Results and discussion}

The numbers next to each arrow in the directed graph in Figure 4 show the number of participants selecting each option (percentages sum to $100 \%$ across the two options offered in any particular question). The first observation, seen in the numerical labels at the very top of the figure, is that 152 out of 193 participants (79\%) preferred to undergo the shock immediately. This is about twice the percentage of participants in Study 2 who chose to undergo a bee sting immediately, perhaps because the shocks were perceived as more unfamiliar and threatening. Of these 152 participants, $68 \%$ made the same choice even when the delayed shock would be reduced by $4 \mathrm{~V}$, and of those, $77 \%$ held to the choice even when the delayed shock was reduced by a further $4 \mathrm{~V}$. Thus, $41 \%$ of all participants (79 out of 193) preferred immediate shock even to a shock they were told to regard as $20 \%$ less intense, to be delivered in 1 week. This provides further convergent validation of the basic findings of the first three studies.

Of particular interest, however, is the behavior of the 103 participants who preferred a $40-\mathrm{V}$ immediate shock to a 36-V shock delayed by 1 week. When given the same options with 24 weeks interposed, $76 \%$ of these individuals reversed their preference and chose the more delayed (and lower voltage) shock. This preference reversal was not only frequent - it was in fact the modal response pattern in the study.

Of the 41 participants who chose to put off the shock in the initial question, 22 and 17 made the same choice when the immediate shock was reduced by 4 and $8 \mathrm{~V}$, respectively. Of the 22,12 reversed their choices when a 24-week delay was inserted prior to both options. This pattern of responding, which was quite uncommon in the present study (6\% of all participants), could be interpreted as a "classic" preference reversal predicted by temporal discounting following a hyperbolic function (although other interpretations may be possible).

In sum, the results seem fully consistent with Loewenstein's analysis of why many participants prefer to undergo one-shot aversive experiences immediately, according to which participants anticipate feeling dread that grows sharply with temporal proximity to the event in question.

\section{STUDY 5: TIME COURSE OF PROJECTED AND RECOLLECTED DREAD}

A critical assumption in the foregoing discussion of time preferences is that people anticipate that feelings of dread inspired by a negative event will sharply increase with temporal proximity to the event. Suppose instead that people expected to feel a uniform amount of dread per unit time for an unpleasant event lying in their future regardless of its temporal distance. If this were the case, they should still prefer to undergo the 


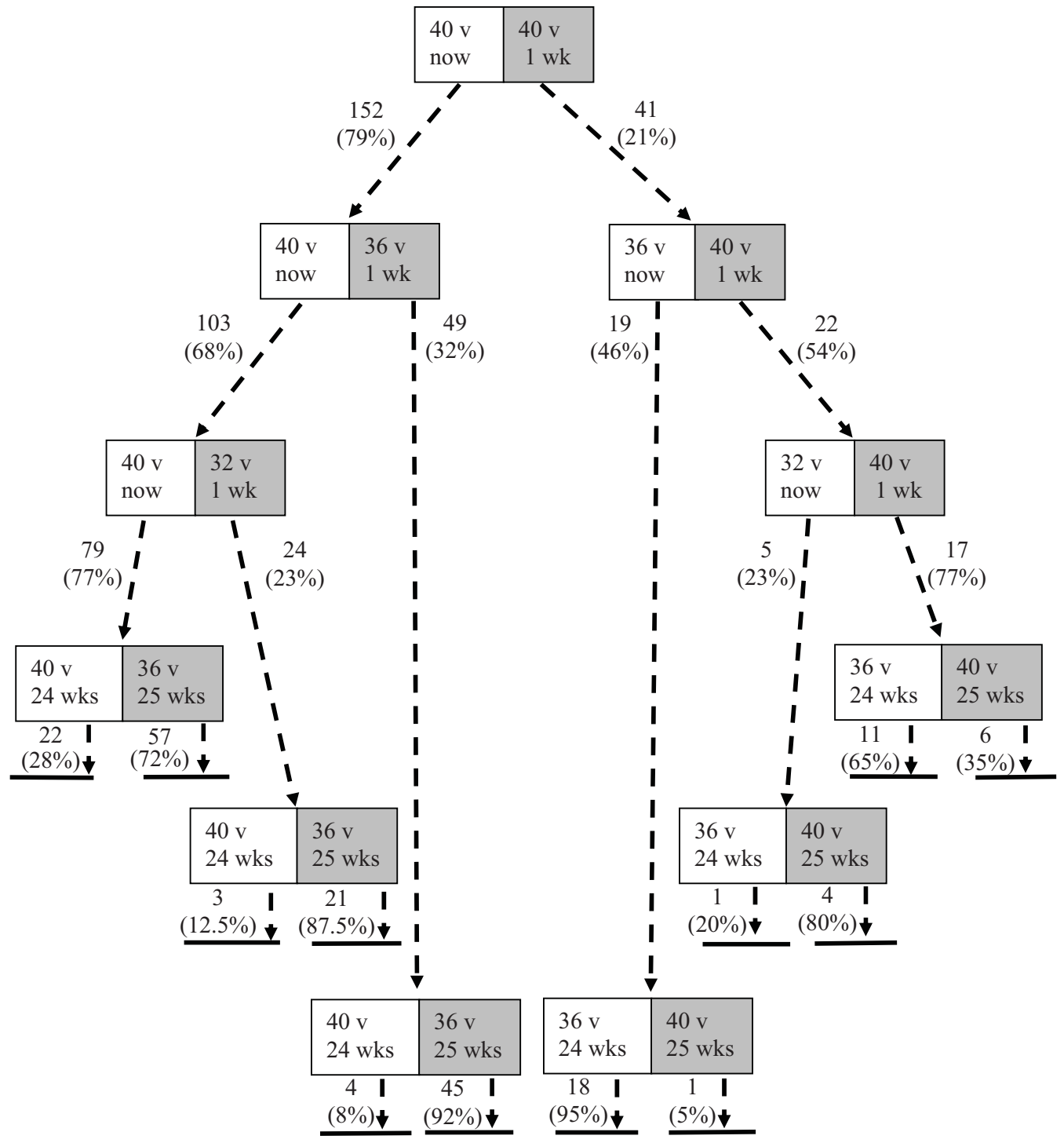

Figure 4. The sequence of options offered to participants in Study 4 and the number of participants choosing each option. (Per cent of participants choosing each of the two options is provided in parentheses.) The top box in the figure illustrates the choice (offered to all participants) between 40-V shock now and 40-V shock in 1 week. The 152 participants picking "now" were then offered the choice of $40 \mathrm{~V}$ now vs. $36 \mathrm{~V}$ in 1 week, etc.

unpleasant experiences sooner rather than later. However, they should not have exhibited the preference reversal documented in Study 3 (accepting a larger punishment now in preference to a smaller one a week from now, but making the opposite choice when 24 weeks were interposed in front of both options).

In the current study, participants estimated the amount of dread they would experience in anticipation of shocks scheduled to occur at various point in the future. They were also asked to recall actual episodes of dread or painful anticipation, and to indicate when they expected the events they were dreading to occur. This made it possible to compare the effect of temporal distance upon hypothetical dread and recollections of real 


\section{Journal of Behavioral Decision Making}

dread experiences. Data on spontaneous experiences of dread in real life contexts are rare, making these data particularly interesting in evaluating the meaningfulness of the hypothetical choices. Given the rarity of data on people's real experiences of dread, it seemed worthwhile for exploratory purposes to also collect a few additional pieces of information about these experiences.

\section{Method}

Participants

Participants were 304 individuals drawn from the same Internet research pool described in Study 1.

\section{Design}

Participants answered demographic questions. They then estimated (using a 1-7 scale) how much dread or painful anticipation they believed they would experience today if they knew they were to receive a $40-\mathrm{V}$ electric shock (1) tomorrow morning, (2) 1 week from now; (3) 1 month from now, and (4) 1 year from now (within-subjects design). In addition, participants were offered five two-alternative choices regarding a hypothetical shock to be experienced either today or in 1 week (the options were 32:40, 36:40, 40:40, 40:36, and 40:32, where $x: y$ refers to the choice of $x \mathrm{~V}$ now versus $y \mathrm{~V}$ in 1 week). Finally, they were asked if, within the past 24 hours, they recalled any experience of dread or painful anticipation of a potential undesirable future event and to indicate how far in the future it lay, the number of times they felt dread in the last day and to estimate the chance of the dreaded event occurring.

\section{Results}

Figure 5 shows the participants' mean estimates of how much dread they would experience today as a function of the temporal distance of a shock. The results show a marked reduction with temporal distance, as suggested by Loewenstein (1987). A very similar pattern was seen in the median reports of anticipated degree of dread $(6,5,4$, and 2, for tomorrow, 1 week, 1 month, and 1 year, respectively). Pairwise differences between these four conditions were all significant $(p<.001)$.

When asked about recollections of actual experiences of painful anticipation or dread within the past 24 hours, $37 \%$ of participants reported having such experiences "more than once" within the preceding 24 hours; $27 \%$ reported "once;" and 36\% did not recall any such experiences. For those who did report such experiences, the median temporal distance of the dreaded event (or the most recent such event, if they could

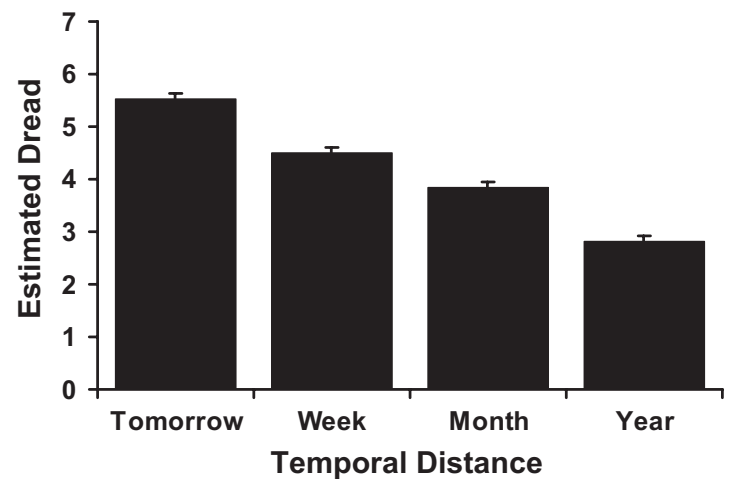

Figure 5. Mean estimates (with standard error) of dread experienced today in anticipation of a 40-V shock reported by participants in Study 5, as a function of the temporal distance between the present time and the time of the shock 


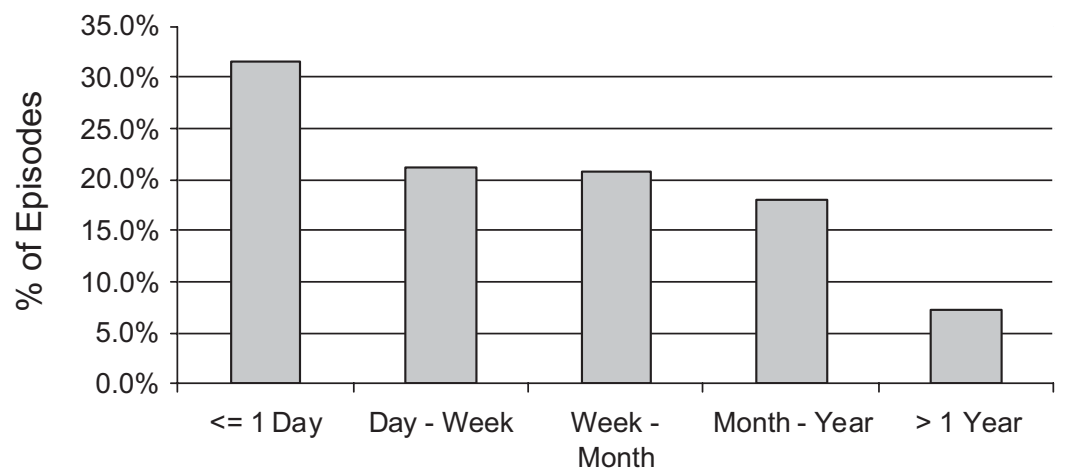

Temporal Distance

Figure 6. Proportion of participants' reports of most recent episode of dread experienced within past 24 hours as a function of the temporal distance of the thing dreaded, from Study 5

think of more than one) was 7 days in the future. Figure 6 shows the per cent of reports lying in five different temporal bins ranging from up to one day to greater than 1 year. Thirty five per cent considered the event they dreaded to have a $100 \%$ chance of occurring, with $16 \%$ estimating the chance at 90 and $10 \%$ estimating it at $80 \%$. Clearly, most dread is of events believed to have a fairly high probability of occurring.

The assessed unpleasantness of the dreaded event varied widely, with a mean of 4.3 and a standard deviation of 1.6 (on a 1-7 scale). Temporal distance of participants' most recent recalled experience of dread was modestly correlated with their estimates of how much dread they would feel over the hypothetical shock in 1 week $(\rho=.14, p<.05), 1$ month $(\rho=.20, p<.01)$ and 1 year $(\rho=.21, p<.005)$, but not over a shock to occur tomorrow. Perhaps this reflects the fact that some individuals are prone to experience dread over temporally distant events, whereas others experience dread only in relation to the immediate future. However, choices regarding the preferred timing of a shock were not significantly correlated with estimates of the amount of dread experienced at any of the four points in time ( $\rho$ ranging from -.04 to .10 ).

Discussion. The results indicate that dread is a very common experience in respondents' lives, with approximately two-thirds of participants recollecting dread within the preceding 24 hours. This finding reaffirms the importance of this barely studied phenomenon. The results also provide some information on the time course of dread. The steep decline of the hypothetical function is consistent with the suggestions of Loewenstein (1987) regarding the effect of temporal distance on dread. Both hypothetical and recollected experiences of dread concentrate very disproportionately on events anticipated within 24 hours, although participants report non-trivial amounts of dread of events far more distant. This is reasonable agreement between subjects' expectations of dread over the shock and their recollected experiences of dreading temporally distant events.

The absence of any detectable correlation across participants between choices regarding preferred timing of shock (now versus 1 week) and estimates of the amount of dread that participants would feel today if faced with the prospect of a 1-week delayed shock is at least superficially inconsistent with the account proposed here. After all, I have been contending that minimizing dread is the chief reason why people choose earlier rather than later shocks. However, assuming that the dread minimization account is correct, there are a number of factors that would be expected to attenuate this correlation. For one, individual differences in estimates of anticipated dread may reflect not only differences in propensity to feel dread, but also differences in people's guesses regarding how painful the shocks themselves will be. For another, the intertemporal choices should reflect not just dread today (as subjects were asked to estimate), but rather total anticipated 


\section{Journal of Behavioral Decision Making}

dread integrated over a week. There are likely to be other attenuating factors as well, including the binary nature of the choice measures. Nonetheless, the lack of any detectable correlation is perhaps puzzling, and might challenge the analysis offered here. Subsequent research could follow up on this by examining perceptions of dread along with perceptions of the intensity of the experience that is being postponed.

\section{GENERAL DISCUSSION}

\section{Conclusions}

The results described here support a number of conclusions. First, Mischel et al. (1969) and Loewenstein (1987) had both presented some evidence indicating that the average participant sometimes chooses to experience unpleasant events sooner rather than later. The results of the present Studies 1 and 2 confirm that this is indeed a widespread (but far from universal) pattern of intertemporal preferences for options that involve various non-monetary aversive experiences, encompassing unpleasant emotional experiences as well as physical pain. By contrast, our data showed that the majority of participants prefer to postpone both monetary losses and property losses as long as possible.

A number of results reported here support the hypothesis that the option to endure unpleasant nonmonetary experiences sooner rather than later (as seen in Studies 1 and 2) is often chosen in order to minimize the experience of dread or painful anticipation of a soon-to-be-experienced harm. First, this account predicts the choice (of about half of the participants) in Study 3 to not learn immediately of the painfulness of an event scheduled to occur at a 1-month delay. This interpretation is also supported by the (classifiable) participants' responses to the question of why they chose to delay this information. Second, this account predicts the preference reversals shown in Study 4: most participants preferred an immediate shock over a slightly milder shock delayed 1 week, whereas they chose the later and milder shock when the same two options were delayed by an extra 24 weeks. This prediction relied upon the assumption that dread grows with temporal proximity to a negative event - an assumption that was directly confirmed by people's reports in Study 5 of their most recent real-life dread experiences.

These results lend support to Loewenstein's (1987) theoretical analysis and main conclusions. It is important to note that the fact people may choose to undergo a negative experience now rather than later in order to minimize dread does not imply that the future negative experiences (monetary or non-monetary) are not discounted. The value of a choice presumably reflects a bundling of different elements: the (discounted) intrinsic value of the experience, summed with estimates of the anticipal pain or pleasure that will occur in the period leading up to the event.

While the present results strongly support the overall analysis proposed by Loewenstein (1987), the details of our empirical results offer a slightly different picture than do some of his results. Recall that Loewenstein reported a study in which 30 undergraduates were asked to indicate how much they would pay to obtain/avoid different outcomes. The mean responses of Loewenstein's participants suggested indifference between shock now and shock delayed by 3 days, whereas we find a strong preference for the immediate shock over options including 1 day and 1 week. This makes sense if people expect to feel a large proportion of the dread within the immediate 3 days preceding an event (consistent with the results of Study 5).

Turning to choices involving losses and gains in money and property, the results obtained here conform much more simply to what one would predict from the classic notion of temporal discounting without requiring any role for anticipatory dread. Similar results were obtained in intertemporal judgments involving loss of a durable good (personal photograph). Why do these kinds of negative events not produce dread that would lead people to choose to experience them earlier rather than later?

As discussed in the Introduction, several differences may play a role. For one thing, some losses may lack emotion related features that promote dread-features that have been variously termed "visceral" (Loewenstein, 1996), "hot" (Metcalfe \& Mischel, 1999), or "affect-rich" (Rottenstreich \& Hsee, 2001). For another, people's appraisals of future monetary losses may be modulated by their awareness of the time value 
of money, and their belief that they will have more money in the future, thereby cushioning the impact of future money losses.

\section{Individual differences}

The present results document the existence of large individual differences in intertemporal choices relating to negative outcomes, an area where most investigators have focused on the median or modal participant or even the mean value of a discounting parameter (the work of Chapman and colleagues being a notable exception; Chapman, 1996; Chapman \& Elstein, 1995).

One rather striking finding, seen in the first two studies, is that there appears to be some-albeit not perfect-coherence to individual differences in intertemporal choices for non-financial negative events. These appear correlated with intertemporal choices for financial losses, but no relationship to intertemporal choices for financial gains (however, given the lack of variability in choices involving monetary options, not much weight should be placed on this). The results reinforce the observation of Frederick et al. (2003) that a single dimension of "time discounting" or "time preference" is likely not tenable. The present data may suggest the existence of a few fairly independent underlying dimensions of time preference. Follow-up research could usefully examine these choices with greater psychometric refinement, e.g., looking at stability across time and reliability across different measures.

Exploration of other measures included in these studies (but not presented here in most cases, for reasons of length) suggest that the relationship between preference for experiencing negative events immediately and self-reported difficulties in real-life self-control is modest, at best. For the most part, linkages in the present data set between "short-sighted behavior" and temporal preferences were not statistically significant. It should be noted that the literature contains a few reports of significant relationships between temporal discounting rates for financial rewards and smoking (Bickel, Odum, \& Madden, 1999) and also heavy drinking (Vuchinich \& Simpson, 1998). One might have expected that temporal preferences for negative experiences (as examined here) would show even stronger relations to self-control problems than temporal preferences for rewards, if self-control problems involve failures to adequately consider the delayed harms caused by immediately pleasurable experiences like smoking or intoxication. However, there is more to selfcontrol than having the "right" preference; there is also holding to one's preferences in the face of temptation (see, e.g., Monterosso \& Ainslie, 1999). For example, the person who in fact often puts off dentistry might not necessarily volunteer that as his or her preferred choice when presented with a choice task like that used here.

One rather exotic feature of the results of the first two experiments is the finding of distributions (of choice variables over participants) having several distinct modes (three modes in Study 1, and two modes in Study 2). It is fairly unusual to find distributions that deviate so dramatically from Gaussian functions. Do these results imply true discontinuities in underlying psychological traits or properties? Not necessarily. Suppose, for example, that these kinds of intertemporal choices depend upon an individual's levels of susceptibility to dread as well as his or her discounting rate for negative experiences. Even if each of these traits has a unimodal (e.g., Gaussian) distribution, it might still be the case that most people's values on the two dimensions would lead them to be seek to choose the earliest possible time, or the latest possible time, from the available options in Study 2. What is not so easy to account for is the apparent trimodality in Study 1, wherein more participants reported indifference between temporal options than report intermediate values, with again greater numbers at the extremes (the W-shaped patterns seen in Figure 1). I would conjecture that many participants may use a decision rule that makes the indifferent response the default choice whenever the inclination to choose one of the alternatives falls below some (evidently fairly high) criterion. In short, while the data might seem to imply the existence of discrete types of people in the realm of intertemporal choice, the underlying traits may actually be distributed in a more typical, i.e., roughly Gaussian, fashion.

However, the present paper has not been able to shed much light on the causes of these individual differences. The topic clearly deserves further investigation, and one potential starting place would be to find 


\section{Journal of Behavioral Decision Making}

out how these choices (about when to experience an aversive event, as in Studies 1, 2, and 4, and also when to learn negative information, as in Study 3) are related to established personality traits.

\section{Gains and losses}

The focus of discussion here has been strictly kept to negative outcomes, rather than positive, simply because the empirical data here shed light only on that domain. However, as Loewenstein's (1987) work suggested, the contrast between monetary and non-monetary outcomes, and the role of "anticipal" pleasures and pains, may apply as much to positive as to negative events. In Loewenstein's own study, typical participants elected to pay more for a kiss from a movie star to be experienced in 3 days than they did for the same kiss to be experienced now; as he noted, one natural explanation would be that this allows them to anticipate with pleasure the experience over the 3 days. By contrast, they preferred to take a gain of $\$ 4$ immediately. One issue that deserves further investigation is the relationship across individuals between pleasant anticipation and dread; it would be interesting indeed if some individuals focus entirely on the first-order hedonic consequences while others tend to more heavily factor in their own anticipal experiences, both positive and negative.

\section{Limitations}

One limitation of the present work is the use of hypothetical responses (except for the self-reports of dread in Study 5). The use of actual rather than hypothetical incentives has sometimes been found to affect patterns of choices (e.g., Holt \& Laury, 2001), and it would certainly be instructive to examine choices about aversive experiences participants actually anticipate undergoing. Indeed, a few studies conducted in the 1960s asked participants to choose between an immediate annoying shock and a shock delayed by a number of seconds (e.g., Cook \& Barnes, 1964; Hare, 1966). Many participants chose to receive the punisher immediately rather than at a delay, consistent with the present results. However, it seems doubtful whether it would be feasible or ethical to carry out such studies for the more severe sorts of non-monetary experiences that were the focus of the present paper. Christensen-Szalanski (1984) reported that many women indicate a preference for abstaining from the use of anesthesia in childbirth, but when they begin to experience the actual pain of childbirth, change their minds and request anesthesia. This "preference reversal" could be viewed as evidence of negative temporal discounting for pain, but this might be misleading, if the reversal occurs only when pain is actually being experienced.

\section{Questions for future research}

As described in the Introduction to the present paper, the topic of dread of future unpleasant experiences has been little studied in the context of decision making, despite its relevance to many socially important problems. Not surprisingly, therefore, there are a great many interesting questions that deserve future investigation. A very basic question (raised by an anonymous reviewer of this paper) is whether dread is distinct from fear. While fear clearly plays a large role in many instances of dread, and many of the scenarios explored here would seem to include a predominant element of fear, it would seem that dread may often include a broad array of emotions and cognitions besides fear. Another obvious question is what makes certain harms evoke dread more than others. The results of the present study suggest that the prospect of (at least moderate) losses of money or tangibles does not produce much dread, but one suspects that expectation of far greater monetary losses might well produce it. However, it does not seem that severity can be the only factor involved. While the prospect of a bee sting was evidently judged sufficient to trigger substantial dread for most of my participants, an unpublished study carried out in my lab disclosed that the median participant from the population examined here demands only $\$ 100$ to undergo a pain described as equivalent to a bee sting. 
Another question is whether dread-minimizing time choices involving relatively long time intervals, such as those studied here, mirror participants' choices in very short-term situations such as the studies in which participants were allowed to delay electric shocks by a number of seconds (Cook \& Barnes, 1964; Hare, 1966).

In sum, though little investigated in the psychological and behavioral-economic literature, the goal of minimizing dread seems likely to play a very important role in people's everyday choices (as suggested by participants' direct reports in Study 5). The results described here bolster the idea that attempts to minimize dread probably have significant effects on a large range of different life choices that people make, as writers such as Mischel and Loewenstein have proposed. This is also an emotion for which, judging from the present results, striking individual differences seem to exist. These matters appear ripe for further investigation, and the present results suggest a number of promising directions for such work.

\section{ACKNOWLEDGEMENTS}

The author is grateful to Jon Baron and Hal Pashler for useful discussions and comments, and to Ed Vul for web programming. The work was supported by the National Institute of Mental Health (MH45584).

\section{REFERENCES}

Ainslie, G. (1992). Picoeconomics: The strategic interaction of successive motivational states within the person. Cambridge, UK: Cambridge University Press.

Bickel, W. K., Odum, A. L., \& Madden, G. J. (1999). Impulsivity and cigarette smoking: Delay discounting in current, never, and ex-smokers. Psychopharmacology, 146, 447-454.

Chapman, G. B. (1996). Temporal discounting and utility for health and money. Journal of Experimental Psychology: Learning, Memory, and Cognition, 22, 771-791.

Chapman, G. B. (1998). Sooner or later: The psychology of intertemporal choice. The Psychology of Learning and Motivation, 38, 83-113.

Chapman, G. B., \& Elstein, A. D. (1995). Valuing the future: Temporal discounting of health and money. Medical Decision Making, 15, 373-386.

Chapman, G. B., \& Winquist, J. R. (1998). The magnitude effect: Temporal discount rates and restaurant tips. Psychonomic Bulletin \& Review, 5, 119-123.

Christensen-Szalanski, J. (1984). Discount functions and the measurement of patients' values. Medical Decision Making, $4,47-58$.

Cook, J. O., \& Barnes, L. W. (1964). Choice of delay of inevitable shock. Journal of Abnormal and Social Psychology, 68, 669-672.

Critchfield, T. S., \& Kollins, S. H. (2001). Temporal discounting: Basic research and the analysis of socially important behavior. Journal of Applied Behavior Analysis, 34, 101-122.

Dread. (1990). Webster's new collegiate dictionary (9th ed.). Springfield, MA: Merrian-Webster Inc.

Dread. (2009). The free dictionary. Retrieved from http://www.thefreedictionary.com, 28 April 2010.

Ellermeier, W., Westphal, W., \& Heidenfelder, M. (1991). On the "absoluteness" of category and magnitude scales of pain. Perception \& Psychophysics, 49, 159-166.

Elster, J. (1999). Alchemies of the mind: Rationality and the emotions. Cambridge, UK: Cambridge University Press.

Frederick, S., Loewenstein, G., \& O'Donoghue, T. (2003). Time discounting and time preference: A critical review. In G. Loewenstein, D. Read , \& R. Baumeister (Eds.), Time and decision: Economic and psychological perspectives on intertemporal choice (pp. 13-85). New York: Russel Sage Foundation.

Green, L., Myerson, J., \& McFadden, E. (1997). Rate of temporal discounting decreases with amount of reward. Memory \& Cognition, 25, 715-723.

Hare, R. D. (1966). Preference for delay of shock as a function of its intensity and probability. Psychonomic Science, 5 , 393-394.

Holt, C. A., \& Laury, S. K. (2001). Varying the scale of financial incentives under real and hypothetical conditions. Behavioral and Brain Sciences, 24, 417-418. 


\section{Journal of Behavioral Decision Making}

Jevons, W. S. (1905). Essays on economics. London: Macmillan.

Kirby, K. N., \& Marakovic, N. N. (1996). Delay-discounting probabilistic rewards: Rates decrease as amounts increase. Psychonomic Bulletin and Review, 3, 100-104.

Krantz, J. H., \& Dalal, R. (2000). Validity of web-based psychological research. In M. Birnbaum (Ed.), Psychological experiments on the Internet. San Diego: Academic Press.

Loewenstein, G. F. (1987). Anticipation and the valuation of delayed consumption. Economic Journal, 97, 666-684.

Loewenstein, G. F. (1996). Out of control: Visceral influences on behavior. Organizational Behavior and Human Decision Processes, 65, 272-292.

Metcalfe, J., \& Mischel, W. (1999). A hot/cool-system analysis of delay of gratification: Dynamics of willpower. Psychological Review, 106, 3-19.

Mischel, W., Grusec, J., \& Masters, J. C. (1969). Effects of expected delay time on the subjective value of rewards and punishments. Journal of Personality and Social Psychology, 11, 363-373.

Monterosso, J., \& Ainslie, G. (1999). Beyond discounting: Possible experimental models of impulse control. Psychopharmacology, 146, 339-347.

Myerson, J., \& Green, L. (1995). Discounting of delayed rewards. Journal of the Experimental Analysis of Behavior, 64, 263-276.

Navarick, D. J., \& Fantino, E. (1976). Self-control and general models of choice. Journal of Experimental Psychology: Animal Behavior Processes, 2, 75-87.

Ostaszewski, P., \& Karzel, K. (2002). Discounting of delayed and probabilistic losses of different amounts. European Psychologist, 7, 295-301.

Rachlin, H. (2000). The science of self-control. Cambridge, MA: Harvard University Press.

Rachlin, H., Rainieri, A., \& Cross, D. (1991). Subjective probability and delay. Journal of the Experimental Analysis of Behavior, 55, 233-244.

Rottenstreich, Y., \& Hsee, C. K. (2001). Money, kisses, and electric shocks: An affective psychology of risk. Psychological Science, 12, 185-190.

Stanton, J. M., \& Weiss, E. M. (2002). Online panels for social science research: An introduction to the study response project. Report No. 13001, School of Information Studies, Syracuse University, Syracuse, NY.

Thaler, R. (1981). Some empirical evidence on dynamic inconsistency. Economic Letters, 8, 201-207.

Vuchinich, R. E., \& Simpson, C. A. (1998). Hyperbolic temporal discounting in social drinkers and problem drinkers. Experimental and Clinical Psychopharmacology, 6, 292-305.

Yates, J. F., \& Watts, R. A. (1975). Preferences for deferred losses. Organizational Behavior and Human Performance, 13, 294-306.

Authors' biographies:

Christine R. Harris is an Associate Professor in the Department of Psychology at the University of California, San Diego. Her research interests focus on human emotions and their connections to cognitive processes and decision-making, including dread, gender differences in risk, and effects of shame and embarrassment in health-care decision-making.

Author's address:

Christine R. Harris, Department of Psychology - 0109, University of California, San Diego, 9500 Gilman Drive, La Jolla, CA 92093-0109, USA. 